\title{
Update on Hemicrania Continua
}

\author{
Elisabetta Cittadini • Peter J. Goadsby
}

Published online: 16 November 2010

(C) The Author(s) 2010. This article is published with open access at Springerlink.com

\begin{abstract}
Hemicrania continua $(\mathrm{HC})$ is a rare primary headache syndrome, characterized by unilateral pain and an absolute response to indometacin. Since the term was first coined in 1984, more than 100 cases have been described worldwide. Most recently, detailed case series that provide more detailed information concerning the sometimes complex clinical presentation of $\mathrm{HC}$ have been reported. Functional imaging studies suggest a unique pattern of subcortical involvement in HC: contralateral to the pain posterior hypothalamic region, ipsilateral dorsal pons and ipsilateral ventral midbrain, which, along with the particular effect of indometacin, probably justifies its classification as a unique entity. Increasing the awareness of this primary headache form among clinicians will aid in its diagnosis while further work is being undertaken to characterize the syndrome.
\end{abstract}

Keywords Chronic daily headache $\cdot$ Indometacin-sensitive headache - Indometacin test - Trigeminal autonomic cephalalgias · International classification of headache disorders

\section{Introduction}

The first description of the syndrome was probably as a cluster headache variant with strictly unilateral, continuous

\footnotetext{
E. Cittadini

Functional Magnetic Resonance Imaging of the Brain Centre, Pain Group, Oxford University,

Oxford, UK

e-mail: cittadin@fmrib.ox.ac.uk

P. J. Goadsby $(\square)$

San Francisco, UCSF Headache Center, University of California, 1701 Divisadero Street, Suite 480,

San Francisco, CA 94115, USA

e-mail: pgoadsby@headache.ucsf.edu
}

headache responding to indometacin [1]. Subsequently, the disorder was named hemicrania continua (HC) [2]: the index patients were a woman (age 63 years) and a man (age 53 years) who developed a strictly unilateral continuous pain from onset and were completely responsive to indometacin. Interestingly, 1 year earlier, a 49-year-old man who had a history of more than 20 years of unilateral pain, mainly localized on the left side, and also had a dramatic response to indometacin was described [3].

\section{Case Series}

Following the description by Sjaastad and Spierings [2], more than 100 cases of $\mathrm{HC}$ have been described. The first case series was reported in 1991 with 18 cases reviewed from the literature [4]. Newman and colleagues [5] described 10 new cases and reviewed 24 cases from the literature in an attempt to better describe the clinical picture and temporal profile. In 1999, Espada and colleagues [6] described the long-term outcome of the indometacin response in five men and four women. Peres and colleagues [7] described 34 new cases to highlight this syndrome, and Pareja and colleagues [8] reviewed 16 patients with $\mathrm{HC}$ to assess doses and the side effects of prolonged indometacin treatment. Bigal and colleagues [9] retrospectively described 10 cases, and Wheeler [10] described six cases of $\mathrm{HC}$ in African-Americans. Klein and colleagues [11] retrospectively described eight patients with $\mathrm{HC}$ that had neuro-ophthalmologic presentations. In 2009, Marmura and colleagues [12•] retrospectively reviewed the clinical charts of 43 patients with positive response to indometacin versus 122 patients with a negative response to indometacin to identify possible clinical differences, which is in practice a very substantial issue. The authors compared the two groups for age, sex, presence or absence of specific autonomic symptoms, medication overuse, rapid onset of 
headache, and if the headaches met International Headache Society (IHS) criteria for migraine when severe. The study did not show any difference in the demographics or clinical characteristics of these two groups, supporting the clinical impression that it is challenging to identify clinical characteristics that can predict a response to indometacin. In the study, the frequent diagnosis of patients who did not respond to indometacin included chronic migraine with and without medication overuse, new daily-persistent headache (NDPH), nummular headache, or cervicogenic headache [13]. Further, 24 of 42 patients $(57 \%)$ had cranial autonomic features required by the International Classification of Headache Disorders (ICHD) [14] and 55\% of the patients exhibited medication overuse. In a previous study [7], 25 of 34 patients $(73.5 \%)$ had at least one cranial autonomic feature according to the Goadsby and Lipton criteria [15], and in the most recent study [16••], 37 of 39 patients $(95 \%)$ with $\mathrm{HC}$ had at least one cranial autonomic feature. However, some of the features in the cohort are not in the current diagnostic criteria, including forehead/facial flushing, itching of the eye, eyelid edema, and a sense of aural fullness or swelling. In addition, 3 of 39 patients had side-shifting pain, and there are reports of patients with side-shifting pain in the literature [16*•]. Overall, it emerged that some of the current criteria for $\mathrm{HC}$ [14] are restrictive and that there is a need for the revision of the current criteria.

\section{Epidemiology and Sex Distribution}

The incidence and prevalence of $\mathrm{HC}$ is unknown. Initially, it was considered to be a very rare syndrome. However, the increasing number of patients identified in headache subspecialty clinics has led some to suggest the condition may be underdiagnosed [7, 17]. On the other hand, the diagnosis of a relatively small group of patients with $\mathrm{HC}$ over a period of 13 years [16••] in a tertiary center, using strict indometacin-response criteria, suggests the condition is rare. Only a large populationbased study will properly provide clear information about the prevalence of this condition. In the latest study of 39 patients with $\mathrm{HC}\left[16 \bullet^{\bullet}\right]$, the range of headache onset was between 10 and 67 years, and this data confirms the existing literature that states this condition can begin at any age; the mean age at onset is in the $30 \mathrm{~s}$. In the Vaga study [18], one patient had a clinical picture that resembled $\mathrm{HC}$, but the indometacin trial was not attempted to confirm the diagnosis. This data suggests that the prevalence of $\mathrm{HC}$ is possibly no more than 1 in 1838: in effect, a rare condition.

A preponderance of women (5:1) initially was noted in the first 18 cases reported by Bordini and colleagues [4].
However, the female preponderance has decreased with more reported cases to $1.8: 1$ [5]. In a study of 34 patients, the female-to-male ratio was 2.4:1 [7], and in the recent study of 39 patients [16••], there was a small female preponderance (1.6:1), which is in line with the literature and is less than is seen in patients with migraine.

\section{Family History and Genetics}

A family history of clear HC has not been reported in the available literature. Pareja and colleagues [19] described a patient with episodic $\mathrm{HC}$ who had a sister with $\mathrm{HC}$, but unfortunately, detailed information regarding the headache was not reported. In 1999, a case report describing a coincidental occurrence of familial hemiplegic migraine and primary $\mathrm{HC}$ was suggested to be unlikely to be due to chance because of a very low incidence of both headache types, suggesting a common pathophysiological link [20]. Specific genetic studies have not been carried out in HC, and the rarity of this disorder will make this difficult. In the study of 39 patients with HC [16••], the relationship between the presence of migrainous biology was assessed and it was found that migraine or headache not otherwise specified was present in the family history of $61 \%$ of patients. However, this data does not exclude the possibility that some of the relatives could have $\mathrm{HC}$ because the trial was not assessed due to the design of the study. Therefore, future studies should focus on performing an indometacin trial on the relatives of patients with $\mathrm{HC}$ who have a clinical picture suggestive of $\mathrm{HC}$.

\section{Pathophysiology}

The pathophysiology of $\mathrm{HC}$ is poorly understood. Craniovascular involvement has been investigated with orbital phlebography in six patients, but only in one patient was there an abnormality consisting of bilateral narrowing of the ophthalmic veins, which may have been a nonspecific finding with unilateral pain [21]. The pain pressure thresholds are reported to be reduced in patients with $\mathrm{HC}$ [22], similar to cases of paroxysmal hemicrania and cluster headache $(\mathrm{CH})$ [23]. Pupillometric studies have shown no clear abnormality in HC [24], and studies of facial sweating have shown modest changes similar to those seen in PH [25].

An important development resulting in greater insight into the pathophysiology of primary headache syndrome comes from functional brain imaging that suggested a role for subcortical neural structures [26]. A positron emission tomography study in $\mathrm{HC}$ showed activation of the contralateral posterior hypothalamus, with correlates with hypothalamic activation in $\mathrm{CH}$ and the trigeminal auto- 
nomic cephalalgias (TACs), and also in the dorsal rostral pons, ventrolateral midbrain (extending over the red nucleus and substantia nigra), and pontomedullary junction [27]. The ipsilateral dorsal pontine region is similar to that seen in migraine [28-30]. These findings, together with the clinical phenotype, suggest $\mathrm{HC}$ is unique and overlaps with both TACs and migraine. The complete response to indometacin may be due in part to the activation of the ventral midbrain, red nucleus, and substantia nigra, which is active during the painful exacerbation of $\mathrm{HC}$ and inactive after indometacin administration. It is interesting that TACs and $\mathrm{HC}$ show activation of posterior hypothalamus and prominent cranial autonomic features are present in association with headache.

It has been suggested the cranial autonomic features may be prominent in these syndromes owing to central disinhibition of the trigeminal-autonomic reflex by the hypothalamus [31]. Indeed, there are direct hypothalamic-trigeminal connections [32], and the hypothalamus is known to have a modulatory role on the nociceptive pathways [33]. The activation of the region of the posterior hypothalamus observed in the TACs and HC with neuroimaging studies underlines an important role in the primary headache syndromes for this region. Only further studies and detailed anatomical work will allow us to understand the role of the region more completely in $\mathrm{HC}$ and indeed, more broadly in the TACs.

\section{Clinical Features and Diagnosis}

The current second edition of the ICHD [14] defines HC by the presence of unilateral continuous daily headache without side shift. The pain is considered to be moderate in intensity, but there may be exacerbations of severe pain. During exacerbations, there should be at least one ipsilateral cranial autonomic symptom, such as conjunctival injection, lacrimation, nasal blockage, rhinorrhea, ptosis, or miosis. Cases of patients with side shift of pain have been noted [16••], suggesting the condition is not side locked, and therefore, side shift of pain should not preclude an indometacin trial. The cranial autonomic features do not always occur with the exacerbation of the pain $[7,12 \cdot$, $\left.16 \bullet^{\circ}\right]$ and also, during a detailed interview, a wider range of cranial autonomic features can be detected [16••]. The current IHS classification [14] describes the pain as moderate in intensity with exacerbation of severe pain. From a recent cohort [16••], it emerged that severe pain is reported in $70 \%$ of the patients, reinforcing the importance of timely diagnosis.

In addition, it also has been suggested that unilateral photophobia or phonophobia, or both, are more frequent in $\mathrm{HC}$ and TACs such as $\mathrm{CH}$, paroxysmal hemicrania, and
SUNCT (short-lasting unilateral neuralgiform headache attacks with conjunctival injection and tearing) than in migraine and NDPH [34]. In a cohort of 39 patients [16••], $79 \%$ had phonophobia, which was unilateral in $48 \%$, and $74 \%$ had photophobia, which was unilateral in $48 \%$. The presence of these unilateral symptoms may be clinically useful pointers; however, further comparison studies between $\mathrm{HC}$ and unilateral chronic migraine are needed to confirm the clinical importance of these data.

It also has emerged that more than half of the patients show signs of agitation or restlessness or both, but also, more than half of the patients have sensitivity to movement. This is useful information because it once again suggests that this condition shares some part of the TAC and migraine phenotypes, which is consistent with the functional imaging data. In the future, studies that correlate imaging and phenotype may further elucidate the basis of the symptoms our patients report.

Current criteria [14] for the diagnosis of $\mathrm{HC}$ mandate daily and continuous pain without pain-free periods for more than 3 months. Typically, HC is a chronic condition with the episodic form occurring less often. The current classification [14] does not include criteria that indicate how to classify the chronic and episodic forms based on duration and frequency of the pain. Recent data [16••] confirm that chronic $\mathrm{HC}$ can arise de novo (primary chronic $\mathrm{HC}$ ), or evolve from the episodic subtype (secondary HC). In addition, episodic $\mathrm{HC}$ can arise de novo (primary episodic form), or some patients can switch from chronic to episodic form (secondary episodic). Most of the patients described in this cohort had the primary chronic form, which is in line with the current literature [7]. At present, there is not a clear classification for these two subforms, and the authors suggested the following possible classification: the term chronic should apply to patients without pain-free periods for at least 1 year, and the term episodic should apply to patients who have pain-free periods of at least 1 day.

\section{Differential Diagnosis of Hemicrania Continua}

The differential diagnosis of long-lasting unilateral headache includes $\mathrm{HC}$, unilateral chronic migraine, NDPH (probably largely its migrainous subtype) [35], and the other TACs when they occur with background pain, notably paroxysmal hemicrania. HC can be differentiated from chronic migraine and NDPH by the positive response to indometacin [35]. The differential diagnosis between HC and paroxysmal hemicrania with interictal pain can be difficult, and certainly, a headache diary is very useful during the workup of HC. In our experience, HC typically has less prominent cranial autonomic features than parox- 
ysmal hemicrania. Furthermore, the background pain in $\mathrm{HC}$ is typically more severe than the interictal pain in paroxysmal hemicrania. In addition, painful exacerbations in $\mathrm{HC}$ are long lasting, usually several hours, and less frequent, whereas those in paroxysmal hemicrania are short lasting, typically a few minutes to $1 \mathrm{~h}$, and occur many times a day. In general, a careful history supplemented with a headache diary allows these two headache types to be dissected one from another (Table 1).

\section{Diagnosis and Investigations}

The diagnosis is made on the basis of clinical history, neurological examination, and a therapeutic trial with indometacin. The indometacin test can be performed in two different ways: by making use of an oral trial or a placebocontrolled Indotest test [16]. The mean daily dosage in one cohort was $137 \mathrm{mg}$ with a range of 25-225 mg [7]. In another cohort of 39 patients with HC [16], all patients $(81 \%)$ who could tolerate oral indometacin had an absolute response to the oral trial. The range of effective daily doses in our cohort varied between $50 \mathrm{mg}$ to $500 \mathrm{mg}$ per day. Some three quarters of patients reported side effects at some point, whereas only about a quarter of patients reported side effects during the placebo-controlled Indotest. The latter consists of parenteral single-blind administration of indometacin, 100 or $200 \mathrm{mg}$, or placebo. The authors suggest the placebo-controlled indometacin test may be the gold standard when applied, facilitating diagnosis and research. An important question [12•] that has emerged and has not been addressed yet is whether medication overuse, in particular opioids, can influence the response to indometacin [36]. Medication overuse also has been reported in patients with HC $[16 \bullet \cdot, 37]$ and in our practice, we prefer to stop medication overuse, where it is possible, based on the knowledge that medication can alter the clinical picture [38]. Nevertheless, we performed indometacin trials in both contexts with positive and negative outcome. However, in our original study $\left[16 \bullet^{\bullet}\right]$, we did not specifically address this question. Future clinical and animal studies are needed to advance the knowledge in this specific field.

Table 1 Comparison based on the cohorts of patients with trigeminal autonomic cephalalgia and hemicrania continua

\begin{tabular}{|c|c|c|c|c|}
\hline Headache characteristics & Cluster headache[44] & $\begin{array}{l}\text { Paroxysmal } \\
\text { hemicrania [45] }\end{array}$ & SUNCT/SUNA [46] & Hemicrania continua [16] \\
\hline Sex, M:F & $3: 1$ & $1: 1$ & $1.5: 1$ & $1: 1.6$ \\
\hline \multicolumn{5}{|l|}{ Pain } \\
\hline • Quality & $\begin{array}{l}\text { Sharp/stabbing/ } \\
\text { throbbing }\end{array}$ & $\begin{array}{l}\text { Sharp/stabbing/ } \\
\text { throbbing }\end{array}$ & $\begin{array}{l}\text { Sharp/stabbing/ } \\
\text { throbbing }\end{array}$ & Throbbing/sharp/constant \\
\hline - Severity & Very severe & Very severe & Severe & Moderate/severe/very severe \\
\hline - Distribution ${ }^{\mathrm{a}}$ & $\mathrm{V} 1>\mathrm{C} 2>\mathrm{V} 2>\mathrm{V} 3$ & $\mathrm{~V} 1>\mathrm{C} 2>\mathrm{V} 2>\mathrm{V} 3$ & $\mathrm{~V} 1>\mathrm{C} 2>\mathrm{V} 2>\mathrm{V} 3$ & $\mathrm{~V} 1>\mathrm{C} 2>\mathrm{V} 2>\mathrm{V} 3$ \\
\hline \multicolumn{5}{|l|}{ Attacks } \\
\hline - Frequency (per day) & $1-8$ & 11 & 100 & No pattern \\
\hline - Length, min & $30-180$ & $2-50$ & $1-5$ & 30 min-7 days Background pain \\
\hline \multicolumn{5}{|l|}{ Triggers } \\
\hline - Alcohol & +++ & + & - & + \\
\hline - Nitroglycerin & +++ & + & - & ++ \\
\hline - Cutaneous & - & - & +++ & - \\
\hline Agitation/restlessness & $90 \%$ & $80 \%$ & $65 \%$ & $69 \%$ \\
\hline Episodic vs chronic, E:C & $90: 10$ & $35: 65$ & $10: 90$ & $18: 82$ \\
\hline Circadian/circannual periodicity & Present & Absent & Absent & Absent \\
\hline \multicolumn{5}{|l|}{ Treatment effects } \\
\hline - Oxygen & $70 \%$ & No effect & No effect & No effect \\
\hline - Sumatriptan, $6 \mathrm{mg}$ & $90 \%$ & $20 \%$ & $<10 \%$ & No effect \\
\hline • indometacin & No effect & $100 \%$ & No effect & $100 \%$ \\
\hline \multicolumn{5}{|l|}{ Migraine features with attacks } \\
\hline • Nausea & $50 \%$ & $40 \%$ & $25 \%$ & $53 \%$ \\
\hline - Photophobia/phonophobia & $65 \%$ & $65 \%$ & $25 \%$ & $80 \%$ \\
\hline
\end{tabular}

${ }^{\text {a }} C$ cervical, $V$ trigeminal

SUNA short-lasting unilateral neuralgiform headache attacks with cranial autonomic symptoms, SUNCT short-lasting unilateral neuralgiform headache attacks with conjunctival injection and tearing 
$\mathrm{HC}$ is a debilitating condition [16••], but a recent study clearly showed that it still is misdiagnosed. In fact, in a cohort of 25 patients [39•], not one had received the correct diagnosis before attending the headache center. Interesting$1 y, 85 \%$ of the patients were assessed by a physician within 6 months of the onset of symptoms, but the mean latency of diagnosis was 5 years, with the average number of physicians seen before the headache was correctly diagnosed being $4.6 \pm 2.2$ years. A prompt diagnosis would save hospital resources and relieve the patients more quickly.

\section{Treatment}

There is no other drug that is consistently effective in HC. The essential management problem arises when indometacin produces peptide ulcer disease. Again, the cyclooxygenase- 2 inhibitors seemed to offer a way forward, but are no longer recommended. Topiramate has been reported to be useful in $\mathrm{HC}[40,41]$ and this is born out in practice. Similarly, greater occipital nerve injection with lidocaine and methylprednisolone has been reported to be helpful [42].

In 2008, Burns and colleagues [43・• ] prospectively described a cohort of six patients with $\mathrm{HC}$ that underwent occipital nerve stimulation with a bion device. They found that in a long-term follow-up, four of six patients reported a substantial improvement $(80 \%-90 \%)$, one patient reported a $30 \%$ improvement, and one patient reported that his pain was worse by $20 \%$. The authors suggested the new miniaturized device was safe and effective as it represents a potential new option for the treatment of $\mathrm{HC}$.

\section{Conclusions}

Since Sjaastad and Spierings [2] first coined the term in 1984, our knowledge of $\mathrm{HC}$ has progressed considerably in understanding both the pathophysiology and clinical presentation. It is a severe and disabling condition that deserves a prompt diagnosis. Amendments to the current criteria have been proposed based on the clinical data from a substantial cohort [16••]. The gold standard treatment is indometacin, and occipital nerve stimulation may represent a valid option in a selectgroup of patients. Future directions also will include clinical studies that try to identify possible markers that can help during the differential diagnosis between $\mathrm{HC}$ and unilateral chronic migraine and studies that evaluate whether medication overuse, specifically opioids, can alter the response to indometacin. We suggest that a placebo-controlled indometacin test should be considered the gold standard when applied, facilitating diagnosis and research. We also draw attention to the need for more neurologists and general practitioners to have headache training to reduce the number of patients who still are misdiagnosed.

Disclosures Dr. E. Cittadini: none; Dr. Peter J. Goadsby has served as a board member for Allergan; CoLucid Pharmaceuticals; MAP Pharmaceuticals, Inc.; Merck, Sharpe, and Dohme; Neuralieve; NeurAxon; ATI Pharmaceuticals; Minster Pharmaceuticals; Boehringer-Ingelheim; Boston Scientific; Coherex; Eli Lilly and Co.; Medtronic; and Linde Industrial Gases; has served as a consultant for Bristol-Myers Squibb, Pfizer, NeuroTherapeutics Pharma, Vertex Pharmaceuticals, Valeant, AstraZeneca, and Kalypsys; has provided expert testimony on behalf of MedicoLegal; has received grants or has grants pending with GlaxoSmithKline; MAP Pharmaceuticals, Inc.; Merck, Sharpe, and Dohme; Neuralieve; and Boston Scientific; has received payment for speaking from Merck, Sharpe, and Dohme and Almirall; and has received payment for the development of educational presentations from the American Headache Society.

Open Access This article is distributed under the terms of the Creative Commons Attribution Noncommercial License which permits any noncommercial use, distribution, and reproduction in any medium, provided the original author(s) and source are credited.

\section{References}

Papers of particular interest, published in the last 3 years, have been highlighted as:

- Of importance,

•- Of major importance

1. Medina JL, Diamond S: Cluster headache variant: spectrum of a new headache syndrome. Archives of Neurology 1981, 38:705-709.

2. Sjaastad O, Spierings EL: Hemicrania continua: another headache absolutely responsive to indomethacin. Cephalalgia 1984, 4:65-70.

3. Boghen D, Desaulniers N: Background vascular headache: relief with indomethacin. Can J Neurol Sci 1983, 10:270-271.

4. Bordini C, Antonaci F, Stovner LJ, Schrader H, Sjaastad O: "Hemicrania continua": a clinical review. Headache 1991, 31:20-26.

5. Newman LC, Lipton RB, Solomon S: Hemicrania continua: ten new cases and a review of the literature. Neurology 1994, 44:2111-2114.

6. Espada F, Escalza I, Morales-Asin F, Nasas I, Inignez C, Mauri JA: Hemicrania continua: nine new cases. Cephalalgia 1999, 19:442.

7. Peres MFP, Silberstein SD, Nahmias S, Sechter AL, Youssef I, Rozen TD, Young WB: Hemicrania continua is not that rare. Neurology 2001, 57:948-951.

8. Pareja JA, Antonaci F, Vincent M: The hemicrania continua diagnosis. Cephalalgia 2001, 21:940-946.

9. Bigal ME, Tepper SJ, Rapoport AM, Sheftell FD: Hemicrania continua: comparison between two different classification systems. Cephalalgia 2002, 22:242-245.

10. Wheeler SD: Hemicrania continua in African Americans. J Natl Med Assoc 2002, 94:901-907.

11. Klein JP, Kostina-O'Neil Y, et al.: Neuro-ophthalmologic presentations of hemicrania continua. Am J Ophthalmol 2006, 141:88-92.

12. - Marmura M, Silberstein S, Gupta M: Hemicrania continua: who responds to indomethacin? Cephalalgia 2009, 29:300-307. This is the first retrospective study that tried to identify factors that 
predict responsiveness to indomethacin in patients with the $\mathrm{HC}$ phenotype.

13. Prakash S, Shah ND, Marmura MJ: Hemicrania continua unresponsive to indomethacin do exist. Cephalalgia 2010, 30:123-125.

14. Headache Classification Committee of The International Headache Society: The International Classification of Headache Disorders (second edition). Cephalalgia 2004, 24:1-160.

15. Goadsby PJ, Lipton RB: A review of paroxysmal hemicranias, SUNCT syndrome and other short-lasting headaches with autonomic features, including new cases. Brain 1997, 120:193-209.

16. • Cittadini E, Goadsby PJ: Hemicrania Continua: A clinical study of 39 patients with diagnostic implications. Brain 2010, 133:19731986. This is the largest single-site series of the condition with long-term follow-up.

17. Wheeler S: Clinical spectrum of hemicrania continua. Neurology 2000, 54:422.

18. Sjaastad O, Pettersen H, Bakketeig LS: The Vaga study; epidemiology of headache I: the prevalence of ultrashort paroxysms. Cephalalgia 2001, 21:207-215.

19. Pareja JA, Palomo T, Gorriti MA, Pareja J, Espejo J: Hemicrania episodica- a new type of headache or a pre-chronic stage of hemicrania continua. Headache 1990 1990, 30:344-346.

20. Evers S, Bahra A, Goadsby PJ: Coincidence of familial hemiplegic migraine and hemicrania continua? A case report. Cephalalgia 1999, 19:533-535.

21. Antonaci F: Chronic paroxysmal hemicrania and hemicrania continua: orbital phlebography and MRI studies. Headache 1994, 34:32-34.

22. Antonaci F, Sandrini G, Danilov A, Sand T: Neurophysiological studies in chronic paroxysmal hemicrania and hemicrania continua. Headache 1994, 34:479-483.

23. Antonaci F, Sandrini G, Pucci E, Arrigo A, Micieli G, Nappi G: Lateralization of pain pressure threshold in cluster headache. Cephalalgia 1993, 13:33.

24. Antonaci F, Sand T, Sjaastad O: Hemicrania continua and chronic paroxysmal hemicrania: a comparison of pupillometric findings. Functional Neurology 1992, 7:385-389.

25. Antonaci F: The sweating pattern in hemicrania continua. A comparison with chronic paroxysmal hemicrania. Functional Neurology 1991, 6:371-375.

26. Cohen AS, Goadsby PJ: Functional neuroimaging of primary headache disorders. Expert Review in Neurotherapeutics 2006, 6:1159-1172.

27. Matharu MS, Cohen AS, McGonigle DJ, Ward N, Frackowiak RSJ, Goadsby PJ: Posterior hypothalamic and brainstem activation in hemicrania continua. Headache 2004, 44:747-761.

28. Bahra A, Matharu MS, Buchel C, Frackowiak RSJ, Goadsby PJ: Brainstem activation specific to migraine headache. The Lancet 2001, 357:1016-1017.

29. Afridi S, Giffin NJ, Kaube H, Friston KJ, Ward NS, Frackowiak RSJ, Goadsby PJ: A PET study in spontaneous migraine. Archives of Neurology 2005, 62:1270-1275.

30. Weiller C, May A, Limmroth V, Juptner M, Kaube H, Schayck RV, Coenen HH, Diener HC: Brain stem activation in spontaneous human migraine attacks. Nature Medicine 1995, 1:658-660.

31. Benjamin L, Levy MJ, Lasalandra MP, Knight YE, Akerman S, Classey JD, Goadsby PJ: Hypothalamic activation after stimula- tion of the superior sagittal sinus in the cat: a Fos study. Neurobiology of Disease 2004, 16:500-505.

32. Malick A, Burstein R: Cells of origin of the trigeminohypothalamic tract in the rat. Journal of Comparative Neurology 1998, 400:125-144.

33. Bartsch T, Levy MJ, Knight YE, Goadsby PJ: Differential modulation of nociceptive dural input to [hypocretin] Orexin A and $\mathrm{B}$ receptor activation in the posterior hypothalamic area. Pain 2004, 109:367-378.

34. Irimia P, Cittadini E, Paemeleire K, Cohen AS, Goadsby PJ: Unilateral photophobia or phonophobia in migraine compared with trigeminal autonomic cephalalgias. Cephalalgia 2008, 28:626-630.

35. Goadsby PJ, Boes CJ: New Daily Persistent Headache. Journal of Neurology, Neurosurgery and Psychiatry 2002, 72:ii6-ii9.

36. Jakubowski M, Levy D, Goor-Aryeh I, Collins B, Bajwa Z, Burstein R: Terminating migraine with allodynia and ongoing central sensitization using parenteral administration of COX1/ COX2 inhibitors. Headache 2005, 45:850-861.

37. Young WB, Silberstein SD: Hemicrania continua and symptomatic mediation overuse. Headache 1993, 33:485-487.

38. Warner JS: Analgesic rebound as a cause of hemicrania continua. Neurology 1997, 48:1540-1541.

39. • Rossi P, Faroni J, Tassorelli C, Nappi G: Diagnostic delay and suboptimal management in a referral population with hemicrania continua. Headache 2009, 49:227-234. This is an interesting paper because it highlights that HC still is misdiagnosed and not treated correctly. There is a need for more awareness and understanding of this condition.

40. Camarda C, Camarda R, Monastero R: Chronic paroxysmal hemicrania and hemicrania continua responding to topiramate: two case reports. Clin Neurol Neurosurg 2008, 110:8891.

41. Brighina F, Palermo A, Cosentino G, Fierro B: Prophylaxis of hemicrania continua: two new cases effectively treated with topiramate. Headache 2007, 47:441-443.

42. Afridi SK, Shields KG, Bhola R, Goadsby PJ: Greater occipital nerve injection in primary headache syndromes- prolonged effects from a single injection. Pain 2006, 122:126-129.

43. • Burns B, Watkins L, Goadsby PJ: Treatment of hemicrania continua by occipital nerve stimulation using the novel bion device: long term follow up of six patients. Lancet Neurology 2008, 7:1001-1012. This is an important paper because it is the first study of patients with a bion device. The new miniaturized device was safe and effective as it represents a potential new option for the treatment of $H C$.

44. Bahra A, May A, Goadsby PJ: Cluster headache: a prospective clinical study in 230 patients with diagnostic implications. Neurology 2002, 58:354-361.

45. Cittadini E, Matharu MS, Goadsby PJ: Paroxysmal hemicrania: a prospective clinical study of thirty-one cases. Brain 2008, 131:1142-1155.

46. Cohen AS, Matharu MS, Goadsby PJ: Short-lasting unilateral neuralgiform headache attacks with conjunctival injection and tearing (SUNCT) or cranial autonomic features (SUNA): a prospective clinical study of SUNCT and SUNA. Brain 2006, 129:2746-2760. 